\title{
Antimicrobial Drug Consumption in Emergency Services at North West (Tabuk) Region Hospitals, Saudi Arabia
}

\author{
Yousef Ahmed Alomi* (iD, The Former \\ General Manager of General Administra- \\ tion of Pharmaceutical Care, Former Head, \\ National Clinical Pharmacy and Pharmacy \\ Practice, Former Head, Pharmacy R\&D \\ Administration, Ministry of Health, Riyadh, \\ SAUDI ARABIA.
}

Abeer Hussin Almasoudi, Director, Administration of Research and Studies, Ministry of Health, Tabuk, SAUDI ARABIA. Ghormallah Abdullah Alghamdi, Consultant Family Medicine, General Manager of Health Affairs in Tabuk Region, Ministry of Health, Tabuk, SAUDI ARABIA. Nora Ali Abboud, Clinical Pharmacy Staff, Ministry of Health, Riyadh, SAUDI ARABIA.

\section{Correspondence:}

Yousef Ahmed Alomi, (Bsc. Pharm, MSc. Clin Pharm, BCPS, BCNSP, DiBA, CDE) The Former General Manager of General Administration of Pharmaceutical Care, Former Head, National Clinical pharmacy and pharmacy practice, Former Head, Pharmacy R\&D Administration, Ministry of Health, Riyadh, SAUDI ARABIA.

Phone no: +966 504417712

E-mail:yalomi@gmail.com

Received: 15-12-2018;

Accepted: 13-02-2019

Copyright: $\odot$ the author(s),publisher and licensee Pharmacology, Toxicology and Biomedical Reports. This is an open-access article distributed under the terms of the Creative Commons Attribution NonCommercial License, which permits unrestricted non-commercial use, distribution, and reproduction in any medium, provided the original work is properly cited.

This is an open access article distributed under the terms of the Creative Commons Attribution-NonCommercial-ShareAlike 4.0 License

Access this article online

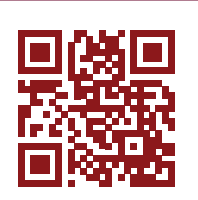

www.ptbreports.org

DOI:

10.5530/PTB.2019.5.20

\begin{abstract}
Objectives: This article describes antimicrobial medication use among different age groups and the cost associated with it in emergency department at Northern West (Tabuk) hospitals, Saudi Arabia. The aim of this study to declare the antimicrobial medication use in emergency Units at North West Region Hospitals, Ministry of Health, Saudi Arabia. Methods: It is a 12-month antimicrobial drug consumption by emergency services at North West region hospitals. It included all adults, pediatrics and neonatal population. The medications were selected by Central Antibiotics committee at $\mathrm{MOH}$ as part of the National Antimicrobial Stewardship program. The consumption is driven from pharmacy database and calculated based on off stranded unit of antimicrobial per hospital. The cost of antibiotics consumption was calculated by using Ministry of Health National Cost database. All cost used was as US currency. Results: The total number of Antimicrobial standard units at Emergency departments were $(8,805.00)$ with average $(1,761.00)$ per hospital. The highest general drug consumption was Azithromycin PO $200 \mathrm{mg} / 15 \mathrm{ml}$ (4253) and Ceftriaxone IV $1 \mathrm{~g}$ (805) and Gentamicin IV $80 \mathrm{mg}$ (401) at Emergency departments. The total cost of antimicrobial consumption was (24,822.60 USD) and (4,964.52 USD) per hospital. The highest cost medication consumption from Adults Emergency departments was $59.85 \%$ (24,822.60 USD) followed by pediatrics Emergency departments 28.99\% (7,197.03 USD) and Neonates Emergency departments of $11.16 \%$ (2,769.98 USD). The highest medication cost was for very broad-spectrum antibiotics like Meropenem IV, Azithromycin PO and Moxifloxacin IV. It consumed more than $60 \%$ of the cost burden. Conclusion: The Emergency department had a high consumption of antimicrobial drugs with burden cost. Antimicrobial stewardship program at Emergency services are necessary to prevent bugs related resistance, improve patient outcome and avoid necessary additional economic burden on healthcare system in the Kingdom of Saudi Arabia.

Keywords: Antimicrobial, Consumption, Emergency, Services, North West (Tabuk), Hospitals, Saudi Arabia.
\end{abstract}

\section{INTRODUCTION}

Over the past few years, several microbes have become resistant to antibiotics marketed in the Kingdom of Saudi Arabia. ${ }^{1-3}$ The resistance has resulted due to misuse of antibiotics and missed doses of antibiotics as per prescribing guidelines. ${ }^{4-6}$ The patient came to the hospital and visited the emergency unit, then the ambulatory care clinic or hospital admission to the regular wards or critical care units. Each hospital provided specialized services to the patients and the patients received the appropriate antibiotics for disease management. The first department visited by the patient was the emergency section. The ER is responsible for treating the acute care of disease with the appropriate medication including antibiotics. The antibiotics utilization or consumption differed from one hospital to another. The general administration of pharmaceutical care at the Ministry of Health established antibiotics stewardship program in $2014 .^{7}$ The program has a strategic plan over five years with several accomplishments and projects including imperial therapy of antibiotics for disease management. Also, a part of the stewardship program was the antibiotics consumption and use at the Ministry of Health hospitals. The analysis of antibiotics consumption before starting the program is necessary to measure the clinical and economic impact of the program. ${ }^{8,9}$ Several investigations showed difference in consumption and utilization of antibiotics from one country to another with an emphasis on emergency services. ${ }^{10,11}$ It is based on antibiotics prescribing regulations and infectious diseases treatment guidelines. To the best of our knowledge there is no investigation in the KSA or Gulf and Middle East countries about antibiotics consumption at ER services.

The goal of the study is to explore the antibiotics consumption at ER in the Northern region (Tabuk) hospitals in the Kingdom of Saudi Arabia.

\section{METHODS}

This study shows a 9-month antimicrobial drug consumption by Emergency department at North West region hospitals which includes all adults, pediatrics and neonatal population. Five hospitals were included included of which hospital 1 has been establish in 1980 to serve 100 beds and its, serves the maternities and pediatrics. Hospital 2 was hospital established in 1990, with the pharmacy care having many departments including, which they are inpatient, outpatient, narcotics, drug information center , clinics and emergency and serve 100 beds, also has most specialties (pediatrics, OR, ICU, ER, nursery, AKU, and SW). Hospital 3 build was built up in 1983, which is containing 100 beds, all also all specialties are available except chemotherapeutic department. 
The pharmacy have several departments, which they are inpatient, outpatient, narcotics and emergency pharmacy. Hospital 4 was started in 1991, the capacity of the hospital is 200 bed, which is the largest in the region and also it does contain verities of specialized and served 7 departments. The pharmacy care units containing five departments which are inpatient, outpatient, narcotics, information center, emergency and clinics department. Hospital 5 hospital was established in 2005, which is the newest although the pharmacy serves 100 beds with different departments they are including inpatient inpatient, outpatient, information centers, narcotics, emergency and clinics, also cover 9 types of wards as the most hospitals in the region. Antibiotics committees were formulated at the above mentioned hospitals through a letter of recommendation which was sent by the General Administration of Pharmaceutical Care at the Ministry of Health for Tabuk Region on October 2013, which stipulates the importance of forming a specialized committee on antibiotics under the supervision and follow up of the department of pharmacy care in the region. Letters of formation of the Antibiotics Committee were sent to all hospitals in Tabuk region in January 2014. In March 2014, this committee was approved by the Director General of Health Affairs in Tabuk Region and guidance to start the application of antibiotics in all hospitals in the region. The actual implementation of the program began in January 2015. The objective of the antibiotic committees was to improve antimicrobial use for hospitalized adults and minimize the emergence and spread of antimicrobial resistance. The objective of the antibiotic committees was to improve antimicrobial use for hospitalized adult and minimizing the emergence and spread of antimicrobial resistance. While the functions of each committees were Supervising the assessment and application of antibiotic strategies in hospitals which are designed by the Antibiotics Committee of the Ministry. Preparation of quarterly reports on the implementation of strategies for the use of antibiotics in hospitals and discussed with the Committee of Pharmacy and therapeutics in the regions. Preparation of bacterial resistance statistics for antibiotics in the area and follow-up and updating. Supervising the training of medical staff (doctors, pharmacists, nurses, specialists, technicians) on the optimal use of antibiotics. Visits to hospitals to ensure the accuracy and validity of the implementation of strategies. Review and analyze indicators of the application of strategies for the use of antibiotics and consider their development in the region of Tabuk. And writing the annual report on the performance, productivity and impact of the program in the region of Tabuk. The antibiotics medications were selected by Central Antibiotics committee at $\mathrm{MOH}$ as part of the National Antimicrobial stewardship program. The consumption is driven from pharmacy database and calculated based on off stranded unit of antimicrobial per hospital. The antimicrobials consisted of antibacterial drugs, antifungal and antiviral medications. The cost of antimicrobial consumption was calculated by using Ministry of Health National Cost database. All cost used was as US currency.

\section{RESULTS}

There were a total of 5 hospitals of which hospitals with 100-300 beds represented $80 \%$ while those with (50-99 beds) were $20 \%$. All hospital (100\%) were accredited by Saudi Board of Hospital Accreditation (CBAHI) while none $(0 \%)$ were accredited by International Joint Commissions. The total months response rate for Emergency departments was $49(36.29 \%)$ that included adults response rate of $18(40 \%)$, pediatrics response rate $22(48.88 \%)$ and neonates response rate $9(20 \%)$ with an average 49 (36.29\%) (Table 1). The total number of Antimicrobial standard units at Emergency departments were $(8,805.00)$ with average $(1,761.00)$ per hospital. The highest consumption from pediatrics was $57.19 \%(5,036.00)$ followed by adult's patient $35.72 \%(3,145.00)$ and neonates $7.09 \%$ (624.00) at Emergency departments. The highest general drug consumption was Azithromycin PO $200 \mathrm{mg} / 15 \mathrm{ml}$ (4253) and
Ceftriaxone IV $1 \mathrm{~g}$ (805) and Gentamicin IV $80 \mathrm{mg}$ (401) at Emergency departments. The highest drug consumption was Azithromycin PO $200 \mathrm{mg} / 15 \mathrm{ml}$ (4253) and Ceftriaxone IV $1 \mathrm{~g}$ (134) at pediatrics Emergency departments. The highest drug consumption was Ceftriaxone IV $1 \mathrm{~g}$ (598) followed by Gentamicin IV $80 \mathrm{mg}$ (291) and Azithromycin PO $250 \mathrm{mg}$ (262) at adults' Emergency departments. The highest drug consumption was Azithromycin PO $200 \mathrm{mg} / 15 \mathrm{ml}$ (83) and Ceftriaxone IV $1 \mathrm{~g}$ (73) at neonates' Emergency departments. The total cost of Antimicrobial consumption was (24,822.60 USD) and (4,964.52 USD) per each hospital. The highest cost medication consumption from Adults Emergency departments $59.85 \%$ (24,822.60 USD) followed by pediatrics Emergency departments 28.99\% (7,197.03 USD) and Neonates Emergency departments $11.16 \%$ (2,769.98 USD). The highest drug cost consumption was Meropenem IV $1 \mathrm{~g}$ (4,039.92 USD) followed by Moxifloxacin IV $400 \mathrm{mg}$ (3,953.00 USD) and Meropenem IV $500 \mathrm{mg}(2,516.00$ USD) at adult's Emergency departments. The highest drug cost consumption was Azithromycin PO $200 \mathrm{mg} / 15 \mathrm{ml}$ (4039.92 USD) followed by Meropenem IV $1 \mathrm{~g}$ (1,066.8 USD) and Meropenem IV $500 \mathrm{mg}$ (748 USD) at pediatrics' Emergency departments. The highest drug cost consumption was Meropenem IV $1 \mathrm{~g}$ (1,066.8 USD) followed by Imipenem + Cilastatin IV $500 \mathrm{mg}$ (550.00 USD) and Meropenem IV $500 \mathrm{mg}$ (544 USD) at neonates' Emergency departments. The highest medication cost was very broad-spectrum antibiotics like Meropenem IV, Azithromycin PO and Moxifloxacin IV. It consumed more than $60 \%$ of the cost burden (Table 2).

\section{DISCUSSION}

In the Northern region, hospitals had emergency services. The emergency services included the medical emergency, surgical, pediatrics, Obstetrics and Gynecology. The study showed huge antibiotic consumption at emergency services. The most antibiotics were consumed by pediatrics followed by adults and neonates. That is related to the number of pediatric cases need for antibiotics; it was more that's adults and neonates. In pediatric cases, the drug most consumed was Azithromycin oral and few cases received Ceftriaxone. That is as the cases of common cold or chest infection demand for antibiotics. The parenteral Ceftriaxone prescribed for many central nervous system infections. In neonates, the same antibiotics consumption pattern was observed as in pediatrics. In adults, the drug most consumed was parenteral Ceftriaxone or intravenous Gentamicin or Azithromycin orally, that's similar to the previous study with ceftriaxone prescribing at emergency units only ${ }^{11}$ and similar study with Azithromycin usage a study. ${ }^{10}$ That may be related to general respiratory disorders or others. The most antibiotics cost consumption was from adults' cases while less cost of pediatrics and neonates. That may be as parenteral Ceftriaxone is more expensive when received by adults than Azithromycin orally received by pediatrics and neonates. Besides; the adults consumed other expensive medications including intravenous Meropenem and Imipenem. Almost three medications consumed sixty percent of the budget which had been used by adult's patient. The emergency hospital services at the northern region at Kingdom of Saudi Arabia is demanding to antibiotics stewardship and prescribing guidelines for adults, pediatrics and neonatal cases. ${ }^{12-14}$ inappropriate antibiotic use is a major constituent of unreasonable drug recommending in children. Our studies recommend that instruction about the lucid use of antibiotics is required for health professionals within the pediatric emergency department setting.

\section{CONCLUSION}

The antibiotic consumption at Emergency services is high. Targeting of antibiotic stewardship program is necessary at North West region hospitals in the Kingdom of Saudi Arabia. Further studies about annual an- 
Table 1: Hospitals demographic data.

\begin{tabular}{|c|c|c|c|c|c|c|}
\hline & Hospital 1 & Hospital 2 & Hospital 3 & Hospital 4 & Hospital 5 & Total \\
\hline \multicolumn{7}{|l|}{ No of Beds } \\
\hline \multicolumn{7}{|l|}{$<50$} \\
\hline $50-99$ & & & & YES & & $1(20 \%)$ \\
\hline $100-300$ & YES & YES & YES & & YES & $4(80 \%)$ \\
\hline \multicolumn{7}{|l|}{$301-400$} \\
\hline \multicolumn{7}{|l|}{$401-500$} \\
\hline CIBAHI & Yes & Yes & Yes & Yes & Yes & $5(100 \%)$ \\
\hline JCI & No & No & No & No & No & $0(0 \%)$ \\
\hline \multicolumn{7}{|c|}{ Repose Rate } \\
\hline \multicolumn{7}{|l|}{ ICU units } \\
\hline Adults & 9 & 9 & 4 & 0 & 9 & $31(68.88 \%)$ \\
\hline Pediatrics & 0 & 6 & 4 & 0 & 8 & $18(40 \%)$ \\
\hline Neonates & 2 & 4 & 4 & 0 & 9 & $19(42.22 \%)$ \\
\hline Total & 11 & 19 & 12 & 0 & 26 & $68(50.37 \%)$ \\
\hline \multicolumn{7}{|c|}{ Inpatient wards } \\
\hline Adults & 9 & 9 & 4 & 9 & 9 & $40(88.88 \%)$ \\
\hline Pediatrics & 7 & 9 & 4 & 9 & 9 & $38(84.44 \%)$ \\
\hline Neonates & 3 & 9 & 4 & 9 & 7 & $32(71.11 \%)$ \\
\hline Total & 19 & 27 & 12 & 27 & 25 & $110(81.48 \%)$ \\
\hline \multicolumn{7}{|c|}{ OPD clinics } \\
\hline Adults & 9 & 9 & 4 & 0 & 8 & $30(66.66 \%)$ \\
\hline Pediatrics & 6 & 8 & 4 & 1 & 7 & $26(57.77 \%)$ \\
\hline Neonates & 0 & 8 & 4 & 0 & 0 & $12(26.66 \%)$ \\
\hline Total & 15 & 25 & 12 & 1 & 15 & $68(50.37 \%)$ \\
\hline \multicolumn{7}{|l|}{ ER units } \\
\hline Adults & 9 & 5 & 4 & 0 & 0 & $18(40 \%)$ \\
\hline Pediatrics & 0 & 9 & 4 & 9 & 0 & $22(48.88 \%)$ \\
\hline Neonates & 0 & 5 & 4 & 0 & 0 & $9(20 \%)$ \\
\hline Total & 9 & 19 & 12 & 9 & 0 & $49(36.29 \%)$ \\
\hline
\end{tabular}

Table 2: Anti-infectious drugs consumption at Emergency departments.

\begin{tabular}{|c|c|c|c|c|c|c|c|c|c|}
\hline $\begin{array}{l}\text { Quantity consumption Anti- } \\
\text { infectious drugs }\end{array}$ & $\begin{array}{l}\text { Dosage } \\
\text { Forms }\end{array}$ & Neonates & $\begin{array}{l}\text { cost } \\
\text { (USD) }\end{array}$ & Pediatrics & $\begin{array}{l}\text { cost } \\
\text { (USD) }\end{array}$ & Adults & cost (USD) & $\begin{array}{c}\text { Total } \\
\text { Quantities }\end{array}$ & $\begin{array}{l}\text { Total } \\
\text { cost } \\
\text { (USD) }\end{array}$ \\
\hline Cloxacillin sodium IV 250mg & Vial or amp. & 0 & 0 & 0 & 0 & 0 & 0 & 0 & 0 \\
\hline Flucloxacillin sodium IV $250 \mathrm{mg}$ & Vial or amp. & 0 & 0 & 0 & 0 & 0 & 0 & 0 & 0 \\
\hline Piperacillin + Tazobactam IV $2.25 \mathrm{~g}$ & Vial & 20 & 27.2 & 30 & 40.8 & 100 & 136 & 150 & 204 \\
\hline Piperacillin + Tazobactam IV $4.5 \mathrm{~g}$ & Vial & 10 & 21.87 & 10 & 21.87 & 110 & 240.54 & 130 & 284.27 \\
\hline Ceftazidime IV 1g & Vial & 31 & 23.15 & 40 & 29.87 & 110 & 82.14 & 181 & 135.15 \\
\hline Ceftriaxone IV $1 \mathrm{~g}$ & Vial & 73 & 54.02 & 134 & 99.16 & 598 & 442.52 & 805 & 595.7 \\
\hline Cefepime IV $1 \mathrm{~g}$ & Vial & 20 & 37.52 & 20 & 37.52 & 40 & 75.04 & 80 & 150.08 \\
\hline Cefepime IV 2g & Vial & 46 & 159.47 & 55 & 190.67 & 154 & 533.87 & 255 & 884.01 \\
\hline $\begin{array}{l}\text { Imipenem + Cilastatin IV } \\
500 \mathrm{mg}+500 \mathrm{mg}\end{array}$ & Vial & 50 & 550 & 55 & 605 & 165 & $1,815.00$ & 270 & $2,970.00$ \\
\hline Meropenem IV 500mg & Vial & 40 & 544 & 55 & 748 & 185 & $2,516.00$ & 280 & $3,808.00$ \\
\hline Meropenem IV $1 \mathrm{~g}$ & Vial & 40 & 1066.8 & 40 & 1066.8 & 150 & $4,000.50$ & 230 & $6,134.10$ \\
\hline Tigecycline IV 50mg & Vial & 0 & 0 & 0 & 0 & 0 & 0 & 0 & 0 \\
\hline
\end{tabular}




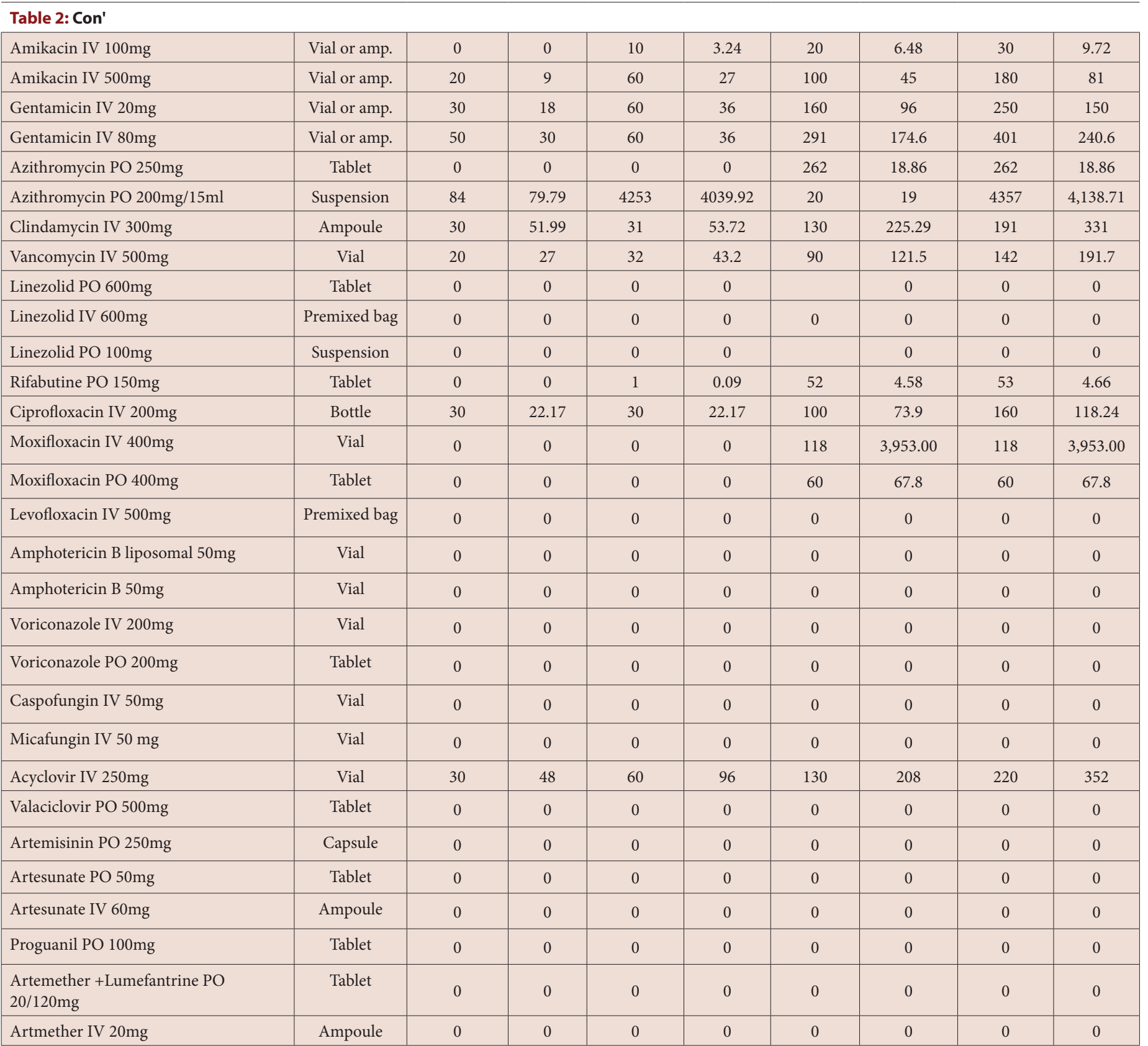

tibiotic consumption and utilization are highly recommended in Saudi Arabia.

\section{ACKNOWLEDGEMENT}

Non.

\section{CONFLICT OF INTEREST}

The authors declare no conflict of interest.

\section{ABBREVIATIONS}

ER: Emergency; KSA: Kingdom of Saudi Arabia; MOH: Ministry of Health; OR: Operation; ICU: Intensive Care Unit; AKU: Artificial Kidney Unit; SW: Surgical Wards; UDS: Unite State Dollars.

\section{ORCID ID}

Yousef Ahmed Alomi (iD https://orcid.org/0000-0003-1381-628X

\section{REFERENCES}

1. AlYousef SA. Surveillance of antibiotic-resistant bacteria in King Khalid hospital, Hafr Al-Batin, Saudi Arabia, during 2013. Jundishapur J Microbiol. 2016;9(9):e19552.

2. Lakshmana GK, Marie MAM, Al-Sheikh YA, John J, Gopalkrishnan S, Chikkabidare SP, et al. A 6-year surveillance of antimicrobial resistance patterns of Acinetobacter baumannii bacteremia isolates from a tertiary care hospital in Saudi Arabia during 2005-2010. Libyan J Med. 2014;9(1):24039.

3. Aly $\mathrm{M}$, Balkhy $\mathrm{HH}$. The prevalence of antimicrobial resistance in clinical isolates from Gulf Corporation Council countries. Antimicrob Resist Infect Control. 2012;1(25):1-5.

4. Aref ABA, Mohamad AA, Mohammed AA, et al. MSR and IMT. Non prescribed sale of antibiotics in Riyadh, Saudi Arabia: A Cross Sectional Study. Clin Microbiol Infect. 2016;2(1):561.e7-19. 
5. Alnemri AR, Almaghrabi RH, Alonazi N, Alfrayh AR. Misuse of antibiotic: A systemic review of Saudi published studies. Curr Pediatr Res. 2016;20(12):169-73.

6. Saati NS, Sedy AMS, Boqursain SK. Impact of antibiotic consumption on antibiotic resistance. EC Microbiol. 2017;2:69-75

7. Alomi YA. National Antimicrobial Stewardship Program in Saudi Arabia: initiative and the future. Open Access J Surg. 2017;4(5):1-7.

8. Borde JP, Kern WV, Hug M, Steib-Bauert M, DeWith K, Busch HJ, et al. Implementation of an intensified antibiotic stewardship programme targeting third-generation cephalosporin and fluoroquinolone use in an emergency medicine department. Emerg Med J. 2015;32(7):509-15.

9. Lee CF, Cowling BJ, Feng S, Aso H, Wu P, Fukuda K, et al. Impact of antibiotic stewardship programmes in Asia: A systematic review and meta-analysis. J Antimicrob Chemother. 2018;73(4):844-51.
10. Al-Niemat SI, Aljbouri TM, Goussous LS, Efaishat RA, Salah RK. Antibiotic prescribing patterns in outpatient emergency clinics at Queen Rania Al Abdullah II Children's Hospital, Jordan, 2013. Oman Med J. 2014;29(4):250-4.

11. Oqal MKA, Elmorsy SA, Alfhmy AK, Alhadhrami RM, Ekram RA, Althobaiti IA, et al. Patterns of antibiotic prescriptions in the outpatient department and emergency room at a Tertiary Care Center in Saudi Arabia. Saudi J Med Med Sci. 2015;3(2):124-9.

12. Enani MA. The antimicrobial stewardship program in Gulf Cooperation Council (GCC) states: Insights from a regional survey. J Infect Prev. 2016;17(1):16-20.

13. Trinh TD, Klinker KP. Antimicrobial Stewardship in the emergency department. Infect Dis Ther. 2015;4(1):39-50.

14. Bishop BM. Antimicrobial Stewardship in the emergency department: Challenges, opportunities and a call to action for pharmacists. J Pharm Pract. 2016;29(6):556-63. 